\title{
Autocuidado domiciliar após cirurgias ginecológicas: elaboração e validação de material educativo
}

Home self-care after gynecological surgeries: elaboration and validation of educational material Autocuidado domiciliario después de cirugías ginecológicas: elaboración y validación de material educativo

Maria Laura Rodrigues Lins ${ }^{1}$ i hitps://orcid.org/0000-0002-3404-9940

Carla Braz Evangelista ${ }^{1}$ i nttps://orcid.org/0000-0001-7063-1439 Gabriela Lisieux Lima Gomes ${ }^{1}$ ib hitps://orcid.org/0000-0002-7032-2035 Jaqueline Queiroz de Macedo ${ }^{1}$ ic nttps://orcid.org/0000-0002-1330-3460

Como citar:

Lins ML, Macedo JQ, Evangelista CB, Gomes GL. Home self-care after gynecological surgeries: elaboration and validation of educational material. Acta Paul Enferm. 2021;34:APE03154.

DOI

http://dx.doi.org/10.37689/actaape/2021A003154

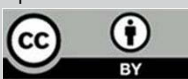

Descritores

Autocuidado; Promoção da saúde; Procedimentos cirúrgicos em ginecologia; Materiais educativos e

de divulgação; Estudos de validação

Keywords

Self care; Health promotion; Educational and promotional materials; Gynecologic surgical

procedures

Descriptores

Autocuidado; Promoción de la salud Procedimientos quirúrgicos ginecológicos; Materiales educativos y de divulgación

Submetido 3 de Dezembro de 2019

Aceito

1 de Março de 2021

Autor correspondente Jaqueline Queiroz de Macedo Email: jaquelineqmac@gmail.com

\section{Resumo}

Objetivo: Construir e validar material educativo com orientações para autocuidado domiciliar no pós-operatório de cirurgias ginecológicas.

Métodos: Estudo metodológico, com coleta efetuada em agosto de 2019, em hospital universitário, por meio da seleção de conteúdo, adaptação da linguagem, inclusão de ilustrações, construção de manual piloto, layoute validação do manual piloto por seis juízes especialistas e 11 mulheres em pós-operatório de cirurgias ginecológica. Utilizaram-se o formulário semiestruturado Suitability Assessment of Materials e o Instrumento de Validação de Conteúdo Educativo em Saúde, para o grupo de juízes, e o formulário semiestruturado e o Suitability Assessment of Materials, para o público-alvo. Análises foram efetuadas mediante estatística descritiva, cálculo do instrumento Suitability Assessment of Materials e do Coeficiente de Validade de Conteúdo do Instrumento de Validação de Conteúdo Educativo em Saúde, além da análise de conteúdo.

Resultados: A cartilha continha oito páginas com orientações sobre motilidade intestinal, manejo da dor, retorno às atividades da vida diária, mecânica corporal, alimentação, prevenção de tromboembolismo venoso, alívio de náusea/vômito, atividade sexual, cuidados com a ferida operatória, sintomatologia e uso de cinta elástica abdominal. Sua validação foi classificada pela maioria dos juízes e pelo público-alvo como "superior". As sugestões dos juízes foram analisadas e incorporadas à versão final, e o público-alvo considerou o material esclarecedor, acessível e necessário. A diagramação contribuiu com a avaliação superior da cartilha.

Conclusão: A cartilha educativa mostrou-se um instrumento válido e confiável para ser utilizado na promoção da saúde de mulheres quanto aos cuidados durante o período pós-operatório de cirurgias ginecológicas no ambiente domiciliar.

\section{Abstract}

Objective: To build and validate educational material with guidelines for home self-care in the postoperative period of gynecological surgeries.

Methods: This is a methodological study, collected in August 2019, at a university hospital, through content selection, language adaptation, inclusion of illustrations, building of a pilot manual, layout and validation of a pilot manual by six expert judges and 11 women in the postoperative period of gynecological surgeries. The semi-structured form Suitability Assessment of Materials and the Educational Content Validation Instrument in Health were used, for the group of judges, and the semi-structured form and the Suitability Assessment of Materials, for the target audience. Analyzes were performed using descriptive statistics, calculation of the Suitability Assessment of Materials instrument and the Content Validity Coefficient of the Educational Content Validation Instrument in Health, in addition to content analysis. 
Results: The booklet contained eight pages with guidelines on intestinal motility, pain management, return to activities of daily living, body mechanics, food, prevention of venous thromboembolism, nausea/vomiting relief, sexual activity, surgical wound care, symptoms and use elastic waistband. Its validation was classified by most judges and by the target audience as "superior". Judges' suggestions were analyzed and incorporated into the final version, and the target audience considered the material to be enlightening, accessible and necessary. The layout contributed to superior assessment of the booklet.

Conclusion: The educational booklet proved to be a valid and reliable instrument to be used in promoting the health of women regarding care during the postoperative period of gynecological surgeries in the home environment.

\section{Resumen}

Objetivo: Elaborar y validar material educativo con instrucciones para el autocuidado domiciliario en el posoperatorio de cirugías ginecológicas.

Métodos: Estudio metodológico, cuya recopilación se realizó en agosto de 2019 en un hospital universitario, mediante la selección de contenido, adaptación del lenguaje, inclusión de ilustraciones, elaboración de manual piloto, diseño y validación del manual piloto por seis jueces especialistas y 11 mujeres en posoperatorio de cirugías ginecológicas. Se utilizó el formulario semiestructurado Suitability Assessment of Materials y el Instrumento de Validación de Contenido Educativo en Salud para el grupo de jueces, y el formulario semiestructurado y el Suitability Assessment of Materials, para el público destinatario. Los análisis fueron realizados mediante estadística descriptiva, cálculo del instrumento Suitability Assessment of Materials y del Coeficiente de Validez de Contenido del instrumento de Validación de Contenido Educativo en Salud, además del análisis de contenido.

Resultados: La cartilla contenía ocho páginas con instrucciones sobre motilidad intestinal, manejo del dolor, retorno a las actividades cotidianas, mecánica corporal, alimentación, prevención de tromboembolismo venoso, alivio de náuseas/vómitos, actividad sexual, cuidados con la herida quirúrgica, sintomatología y uso de faja elástica abdominal. La validación fue clasificada como "superior" por la mayoría de los jueces y por el público destinatario. Las sugerencias de los jueces fueron analizadas e incorporadas en la versión final, y el público destinatario consideró que el material es esclarecedor, accesible y necesario. La maquetación contribuyó con la evaluación superior de la cartilla.

Conclusión: La cartilla educativa demostró ser un instrumento válido y confiable para utilizarse en la promoción de la salud de mujeres con relación a los cuidados durante el posoperatorio de cirugías ginecológicas en el ambiente domiciliario.

\section{Introdução}

A cirurgia ginecológica é um recurso terapêutico para doenças que acometem o trato genital feminino, como mamas e pélvis. No Brasil, entre os anos de 2013 a 2018, foram realizados aproximadamente 1,5 milhão de procedimentos cirúrgicos no aparelho geniturinário, que se concentram em intervençôes ginecológicas de histerectomia (remoção cirúrgica do útero) e colpoperineoplastias (correçóes de prolapsos de órgãos pélvicos). ${ }^{(1-3)}$

A histerectomia é uma das operaçôes ginecológicas realizadas com maior frequência em todo mundo, cujas abordagens para o procedimento podem ser por via abdominal, vaginal ou laparoscópica. ${ }^{(4-6)}$ As colpoperineoplastias objetivam combinar uma boa correção anatômica do prolapso e melhorar os desconfortos, as disfunçóes e a qualidade de vida da paciente. ${ }^{(7,8)}$

Os cuidados pós-operatórios, em especial o domiciliar, requerem açóes voltadas para a ferida operatória, a reorganização do autocuidado com as necessidades humanas básicas e o manejo das atividades da vida diária. Além disso, possíveis alteraçôes, como dor aguda, secreçóes incomuns e sangramentos, devem ser alertadas, uma vez que se associam a maiores riscos de infecçóes e hemorragias. ${ }^{(9)}$ Assim, o planejamento da alta hospitalar deve ser efetuado, respeitando a terapêutica que foi proposta pela equipe de saúde, desde o momento da chegada até a saída do paciente do âmbito hospitalar, visando à redução do tempo de internação e permitindo uma continuidade do cuidado no domicílio. ${ }^{(10)}$ Nesse contexto, a enfermagem tem papel fundamental mediante a educação em saúde e a continuidade dos cuidados na Atenção Primária.

A educação em saúde possibilita a compreensão de informaçôes, favorecendo a adesão ao autocuidado e um compromisso com a própria saúde do sujeito, o que traz implicaçôes positivas em sua recuperação. ${ }^{(11)}$ Para tanto, o enfermeiro, como ente da equipe multiprofissional, pode utilizar tecnologias como facilitadoras de sua relação com o paciente e proporcionar um processo de ensino e aprendizagem mais efetivo. ${ }^{(12)}$ Dentre as tecnologias, ressaltam-se os materiais educativos, como cartilhas, folhetos e cartazes, que são recursos utilizados para gerar comunicaçáo e permitirem a transmissão de conhecimento, simplificando conceitos e proporcionando maior entendimento e memorizaçáo, de forma fácil e dinâmica. ${ }^{(13)}$

O estudo justifica-se devido à lacuna na literatura científica de material educativo para cuidados domiciliares após cirurgias ginecológicas. Nesse 
sentido, a existência de um material instrutivo pode favorecer a uniformização de condutas, a comunicação, a sensibilização para as orientações e a continuidade do cuidado após a alta.

Esta pesquisa teve como objetivo construir e validar material educativo com orientaçóes para o autocuidado domiciliar no pós-operatório de cirurgias ginecológicas.

\section{Métodos}

Estudo do tipo metodológico, que teve como base o desenvolvimento, a elaboração, a validação, a adequação e a finalização de um instrumento educativo direcionado a orientaçóes de autocuidado para pacientes que realizaram cirurgias ginecológicas. ${ }^{(14,15)}$

O estudo foi desenvolvido em um hospital universitário federal de uma capital do Nordeste brasileiro, na clínica obstétrica-ginecológica. Nessa unidade, são atendidas pacientes nos períodos de pré e pós-operatório de cirurgias ginecológicas, contando com equipe multiprofissional especializada.

A amostra foi composta por seis profissionais da saúde que se constituíram em juízes especialistas de variadas áreas da equipe multiprofissional (dois enfermeiros, dois ginecologistas, um fisioterapeuta e um nutricionista) e 11 representantes do público-alvo, ou seja, mulheres em pós-operatório de cirurgias ginecológicas. A amostragem ocorreu por conveniência, em agosto de 2019. O número de juízes participantes do estudo foi sugerido pela literatura. ${ }^{(16)}$

Os critérios de inclusão para a amostra dos juízes especialistas foram: atuar no hospital universitário federal em que se desenvolveu o estudo e em área específica de ginecologia, e desenvolver assistência na clínica ginecológica há pelo menos 6 meses. Foram excluídos os profissionais que estavam afastados de suas atividades no serviço, devido a férias, doença ou outros motivos. Todos os profissionais contatados aceitaram participar da pesquisa. Entretanto, um foi excluído por se encontrar afastado por doença ocupacional.

Para a seleção do público-alvo, os critérios de inclusão foram: mulheres em pós-operatório mediato de cirurgias ginecológicas; internadas na clínica obstétrica-ginecológica e com capacidade cognitiva preservada, alfabetizadas ou analfabetas com acompanhante que soubesse ler e escrever. Foram critérios de exclusão: mulheres em pós-operatório mediato de cirurgias ginecológicas que apresentassem algum desconforto ou complicação pós-operatória ou estivessem sob efeito de medicações que alterassem as funções psíquicas (memória, orientação, pensamento e sono). Dentre as mulheres convidadas, foi excluída uma paciente que estava se sentindo enjoada.

A construção da cartilha foi fundamentada em estudo sobre a elaboração de manuais de orientação para o cuidado em saúde ${ }^{(17)}$ e na classificação das necessidades humanas básicas, conforme a teoria de Wanda Horta. ${ }^{(18)} \mathrm{O}$ estudo seguiu as seguintes etapas: em primeiro lugar, foram realizadas a delimitação e a seleção dos conteúdos mediante revisão conduzida pelo método scoping review, conforme Preferred Reporting Items for Systematic reviews and Meta-Analyses extension for Scoping Reviews (PRIMA$\mathrm{ScR}$ ) cuja descrição é objeto de outro estudo ainda não publicado; em seguida, a linguagem foi adapta$\mathrm{da}$, e as informaçóes aprovadas foram revisadas por um profissional da área de linguística, que buscou organizar os conteúdos presentes no material educativo em mensagens curtas, convidativas e de fácil leitura; na terceira etapa, foi efetuada a seleção dos conteúdos, que incluíram as ilustrações, uma vez que a comunicação visual serve de instrumento para exemplificar instruçóes; ${ }^{(19)}$ na quarta etapa, ocorreu a construção do protótipo do material educativo, a partir da organização sequencial dos conteúdos selecionados em temáticas, os quais foram analisados exaustivamente, para ordenar os assuntos em sequência e facilitar sua compreensão e sua prática pelo público-alvo; na quinta etapa, desenvolveu-se o layout da cartilha, com a contribuição de um profissional da área de design gráfico para confecção do manual piloto (essa última etapa foi realizada antes da validação, por se julgar que a aparência, já no formato de cartilha, elevaria a qualidade e a atração da ferramenta educativa) e, na última etapa, foi feita a qualificaçáo do manual piloto pelos peritos (juízes especialistas) e pelo público-alvo.

A avaliação do material pelos peritos ocorreu após a entrega da cartilha, por meio de respostas ao 
formulário semiestruturado sobre questóes de formação; ao Suitability Assessment of Materials (SAM), validado para o português, que avaliou a qualidade do material educativo a partir dos domínios de conteúdo, exigência de alfabetização, ilustraçóes, layout e apresentação, estimulação do aprendizado e adequação cultural, sendo possível classificar os itens como superior, adequado, não adequado e náo aplicado, por meio de fórmula para calcular seus resultados considerados a partir de valores superiores a 70\%, e o Instrumento de Validação de Conteúdo Educativo em Saúde, que permitiu avaliar especificamente o conteúdo quanto ao seu objetivo, à sua estrutura e à sua relevância, sendo calculado o Coeficiente de Validade de Conteúdo, que é aceitável quando superior a $0,80 .{ }^{(20,21)}$

A avaliação do material pelas representantes do público-alvo ocorreu após a apresentação do projeto, aceite de participação, entrega da cartilha e resposta ao instrumento semiestruturado (sobre questóes sociodemográficas, cuidados do serviço de saúde e a percepção sobre a cartilha) e ao SAM. ${ }^{(20)}$ Para as participantes analfabetas, a leitura foi realizada pelos acompanhantes.

Os dados foram interpretados com o intuito de validar se o material educativo disponibiliza orientaçóes para o autocuidado pertinente às pacientes submetidas a cirurgias ginecológicas. Para tanto, foi utilizada estatística descritiva por meio da descrição da caracterização dos participantes, do cálculo do instrumento SAM, conforme orientação do instrumento, e do cálculo do Coeficiente de Validade de Conteúdo do Instrumento de Validação de Conteúdo Educativo em Saúde, obtido a partir da média de cada item avaliado, dividido pelo valor máximo que o item pode alcançar e sendo considerado o resultado superior aquele com resultados maior que 0,80 . $^{(20)}$

As consideraçóes efetuadas pelos participantes foram analisadas mediante técnica de análise de conteúdo de Bardin, conforme as fases de pré-análise, exploração do material e tratamento, inferência e interpretação dos resultados. A fase de pré-análise consistiu na escolha de documentos para constituição do corpus, formulação de hipóteses e objetivos. Por sua vez, a de exploraçáo do material envolveu a codificação do corpus de análise, a classificação e categorização do material. A fase de tratamento, inferência e interpretação dos resultados envolveu a realização de análises críticas e reflexivas do conteúdo, para que os dados se tornassem significativos e válidos. ${ }^{(22)}$ Essa técnica permitiu a construção das categorias Esclarecimento, Divulgação das orientaçôes e Facilidade de acesso.

Por tratar-se de um projeto que envolveu seres humanos, a fim de receber o aval metodológico e ético, o projeto foi previamente aprovado pelo Comitê de Ética em Pesquisa (CAAE 86689318.5.0000.5183), conforme resolução 466/2012 do Conselho Nacional de Saúde. Todos os participantes assinaram o Termo de Consentimento Livre e Esclarecido. ${ }^{(23)}$

\section{Resultados}

\section{Construção do material educativo}

A partir da scoping review (primeira etapa), foram inclusos 14 estudos, dos quais foram selecionadas 60 enunciações que tratavam das orientações pós-operatórias, sendo organizadas nas temáticas: alimentação, motilidade intestinal, alívio de náusea/ vômito, manejo da dor, retorno às atividades da vida diária, cuidados com a ferida operatória, mecânica corporal, prevenção de tromboembolismo venoso, atividade sexual, sintomatologia, orientação sobre a cinta elástica abdominal e sintomas não esperados. A partir de tais temáticas, sob a égide das necessidades psicobiológicas voltadas para as especificidades das cirurgias ginecológicas, tais conteúdos foram organizados em oito sessões, apresentadas em oito páginas textuais, no formato de brochura e em versão colorida.

\section{Validação do material educativo}

O material educativo foi validado por seis juízes, sendo dois profissionais médicos, dois enfermeiros, um nutricionista e um fisioterapeuta, que atuavam na assistência e no atendimento ginecológico. Os juízes tinham, em média, idade de 36,8 anos (desvio-padrão de 2,92), tempo de formação de 13 anos (desvio-padrão de 2,96) e tempo de experiência em pós-opera- 
tório de 8 anos (desvio-padrão de 6). Todos possuíam titulação acadêmica, variando de especializações até Doutorado, e, além da área hospitalar pós-operatória de especialidade ginecológica, 50\% atuavam em outros serviços ou instituiçôes de ensino.

Os juízes realizaram a avaliação do material a partir da utilização do SAM e do Instrumento de Validação de Conteúdo Educativo em Saúde, conforme resultados apresentados na tabela 1 .

Tabela 1. Avaliação dos itens do Suitability assessment of materials e do Instrumento de Validação de Conteúdo Educativo em Saúde, de acordo com os especialistas

\begin{tabular}{|c|c|c|c|c|}
\hline \multirow[b]{2}{*}{ Domínios do instrumento SAM } & \multicolumn{4}{|c|}{ Fatores de avaliação } \\
\hline & $\begin{array}{c}\text { Superior } \\
\mathrm{n}(\%)\end{array}$ & $\begin{array}{l}\text { Adequado } \\
\mathrm{n}(\%)\end{array}$ & $\begin{array}{c}\text { Não } \\
\text { adequado } \\
\mathrm{n}(\%)\end{array}$ & $\begin{array}{c}\text { Não se } \\
\text { aplica } \\
\mathrm{n}(\%)\end{array}$ \\
\hline Conteúdo & $4(67)$ & $2(33)$ & 0 & 0 \\
\hline Exigência de alfabetização & $4,2(70)$ & 1,8 (30) & 0 & 0 \\
\hline Ilustrações & $4,4(73)$ & $1(17)$ & $0,4(6,7)$ & $0,2(3,3)$ \\
\hline Layout e apresentação & $4,7(78)$ & $1(17)$ & 0 & $0,3(5)$ \\
\hline $\begin{array}{l}\text { Estimulação/ motivação do } \\
\text { aprendizado }\end{array}$ & $4(67)$ & $2(33)$ & 0 & 0 \\
\hline Adequação cultural & $4(67)$ & $1(17)$ & $1(17)$ & 0 \\
\hline SAM - média geral & \multicolumn{4}{|c|}{$83 \%$} \\
\hline IVCES & \multicolumn{4}{|c|}{ CVC } \\
\hline $\begin{array}{l}\text { Objetivos: propósitos, metas e } \\
\text { finalidades }\end{array}$ & \multicolumn{4}{|c|}{0,87} \\
\hline $\begin{array}{l}\text { Estrutura/apresentação: organização, } \\
\text { estrutura, estratégia, coerência e } \\
\text { suficiência }\end{array}$ & \multicolumn{4}{|c|}{0,86} \\
\hline $\begin{array}{l}\text { Relevância: significância, impacto, } \\
\text { motivação e interesse }\end{array}$ & \multicolumn{4}{|c|}{0,86} \\
\hline
\end{tabular}

Algumas porcentagens não somam $100 \%$ devido ao arredondamento. SAM - Suitability Assessment of Materials; IVCES - Instrumento de Validação de Conteúdo Educativo em Saúde; CVC - Coeficiente de Validade de Conteúdo

Por meio do SAM, a qualidade do material educativo foi classificada como "superior" por uma média de 83,3\% dos juízes. Por meio do Instrumento de Validação de Conteúdo Educativo em Saúde, também foi calculado o Coeficiente de Validade de Conteúdo do material educativo para os domínios objetivos, estrutura/apresentação e relevância, que apresentaram resultado superior ao coeficiente que confirmou validação de conteúdo $(>0,80)$. Além das respostas a tais instrumentos de avaliação, os especialistas acrescentaram sugestões para melhoria do material educativo, que foram incluídas na versão final da cartilha. As contribuiçóes fornecidas estão expostas no quadro 1 e referiram-se a mudança de termos, exemplificaçóes e explicaçóes.

Após a avaliação pelos profissionais, o material educativo foi avaliado por 11 pacientes em pós-ope-
Quadro 1. Síntese das mudanças realizadas após sugestões dos juízes avaliadores

\begin{tabular}{|l|l|}
\hline $\begin{array}{l}\text { Consideração } \\
\text { dos juízes }\end{array}$ & Modificações realizadas \\
\hline Troca de termos & Substituído "sim" por "prefira" \\
\cline { 2 - 2 } & Substituído "não" por "evite" \\
\cline { 2 - 2 } & Substituído "macios" por "laxativos" \\
\cline { 2 - 2 } & Substituído "inflamativos" por "inflamatórios" \\
\hline Exemplificação & "facilitem sua digestão ex.: mamão, alface, abobrinha" \\
\cline { 2 - 2 } & "industrializados ex.: embutidos, enlatados, fritos, com muita gordura" \\
\cline { 2 - 2 } & "produzam muitos gases (puns): cebola crua, repolho, batata doce" \\
\cline { 2 - 2 } & "ajudam a cicatrizar: clara de ovo, carnes magras (ex.: frango, peixe), \\
& frutas (ex: caju, acerola, laranja, limão), verduras e legumes variados" \\
\hline Explicações & "Calafrios e febre (se $37,8^{\circ} \mathrm{C}$ ou mais)" \\
\cline { 2 - 2 } & "bastante água (pelo menos 8 copos por dia)" \\
\hline
\end{tabular}

ratório de cirurgias ginecológicas, cuja média de idade foi de 53,8 anos (desvio-padrão de 11,1). Quanto à ocupação, denominaram-se donas de casa $(n=4$; $36,3 \%)$, aposentadas ( $\mathrm{n}=3 ; 27,2 \%)$, secretárias do lar $(\mathrm{n}=2 ; 18,1 \%)$, cuidadora $(\mathrm{n}=1 ; 9 \%)$ ou agricultora $(n=1,9 \%)$. Com relação à escolaridade, sete (64\%) apresentavam ensino fundamental incompleto, três (27\%) ensino médio completo e uma (9\%) não tinha escolaridade. Dentre os tipos de cirurgias, quatro pacientes realizaram histerectomia total abdominal, duas, histerectomia total abdominal com salpingooforectomia, uma histerectomia total vaginal com colpoperineoplastia e quatro colpoperineoplastia. Quanto ao âmbito familiar, nove (82\%) mulheres moravam com algum familiar e duas (18\%) sozinhas; oito $(73 \%)$ relataram ter ajuda de alguém para realizar os serviços domiciliares, e três (27\%) afirmaram que teriam que ir para a casa de algum familiar durante o período de pós-operatório.

Quando questionadas se já tinham recebido orientaçóes dos cuidados do pós-operatório, nove (82\%) negaram, e o restante afirmou ter recebido explicaçóes de graduandas de projeto de extensão universitária sobre orientação para autocuidado após alta hospitalar pós-operatória. Acerca do material educativo, todas o avaliaram como "superior" em todos os domínios (conteúdo, linguagem e aparência) por meio do SAM. Quanto à percepção da cartilha, seguiram as exposiçóes das categorias (Esclarecimento, Divulgação das orientações e Facilidade de acesso).

Com relação à temática Esclarecimento, a seguir estão os depoimentos. 
Olha aqui (falou com a irmã que estava como acompanhante) você estava falando que eu iria ficar oca e sem sentir vontade, mas escute o que tem aqui: a retirada do útero não diminui sua feminilidade, tá vendo isso é tudo psicológico. Ela (irmã) ficou falando aqui que eu não iria mais sentir vontade de nada (relação sexual), mas eu já disse a ele que não tem nada a ver. (Paciente 6)

As orientaçôes que têm, muito boas. Às vezes não sabe, ai vai fazer tudo errado. (Paciente 7)

Qualquer dúvida sobre comida, qualquer coisa vai lá e olha, seguir as instruçóes. Alimentação o que pode e não pode, muito bom, da outra vez que fiz não falaram. Eita, a ducha que eu gosto já estou vendo que não pode, né? Da primeira vez acho que foi até isso (que ocasionou complicaçóes). (Paciente 8)

Outro indicador da importância do material educativo referiu-se à temática Divulgação das orientaçôes, principalmente para membros da família que poderiam ser responsáveis pelo cuidado para com a paciente.

A familia vai entender melhor, a cartilha tá bonita e tem coisas muito importantes. (Paciente 3)

A família já vai ver que não pode fazer as coisas; tem as dicas bem direitinho. (Paciente 4)

Mostrar para a familia, para a família entender. Minha irmá precisa ler. (Paciente 6)

É importante a familia ler, principalmente minha nora que é nova demais. (Paciente 7)

A familia já fica orientada também se precisar fazer, já sabe cuidar dos outros. Era bom já ficar com uma dessa. (Paciente 8)

Acho muito importante, é bom para a família também. (Paciente 11)

Seguem os depoimentos das participantes no que diz respeito à Facilidade de acesso às orientaçôes.
Pra entender, principalmente compreender e tem coisas que tem na cartilha que já tira as dúvidas, principalmente de quem nunca fez cirurgia e não sabe como vai ser. (Paciente 1)

Principalmente as pessoas que fizeram uma primeira cirurgia para tirar as dúvidas é importante. Eo material está ótimo, tá explicando tudo. (Paciente 5)

Após a avaliação das pacientes, o material educativo final foi organizado como segue: Capa - com o título "ORIENTAÇÓES PARA O AUTOCUIDADO DOMICILIAR PÓSCIRURGIAS GINECOLÓGICAS”, autoria e imagem representativa de uma mulher; página 1 - apresentação da cartilha e orientaçóes sobre alimentação; página 2 - orientaçóes para alívio da dor e como evitar trombos; página 3 - orientaçóes para o autocuidado com a ferida operatória e informaçóes sobre sintomas após histerectomia; página 4 - dicas para o cotidiano; página 5 - orientaçôes sobre relação sexual e atividades que devem ser evitadas; página 6 orientaçôes sobre uso de cinta elástica e sintomas não esperados; página 7 - local para disponibilização de informaçóes sobre formas de contato com serviços de saúde; página 8 - título do material, autoria e agradecimento e contracapa (Figura 1).

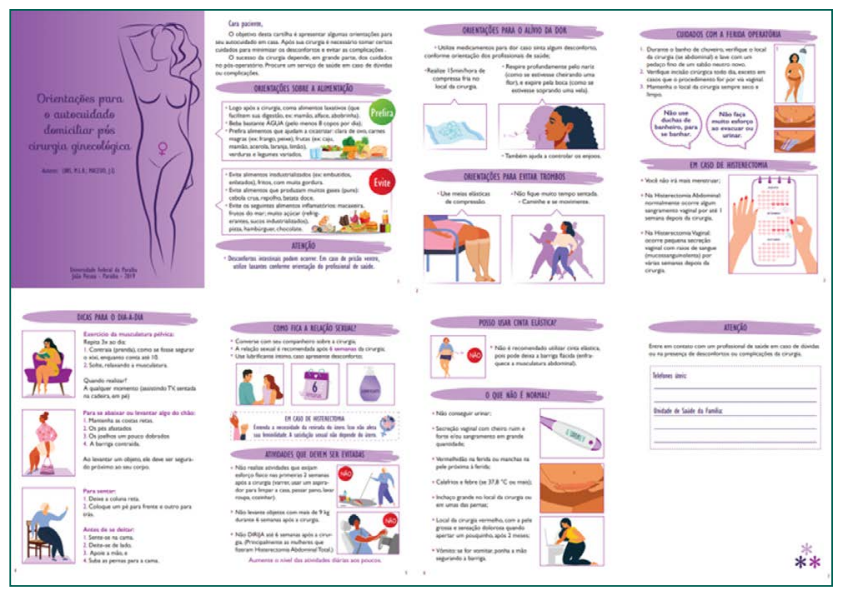

Figura 1. Versão validada da cartilha

\section{Discussão}

O material educativo apresenta fundamentação metodológica que confirma sua validação e possibilida- 
de de ser utilizado em serviços de saúde, como ferramenta educativa para mulheres letradas (ou com cuidador letrado), em pós-operatório de cirurgia ginecológica. A presença dessa tecnologia embasa e faculta a educação em saúde, permitindo que os profissionais, em destaque os enfermeiros, proporcionem cuidados para as pacientes e desenvolvam métodos e formas de gerar um processo de ensino-aprendizagem de acordo com as necessidades, visando à promoçáo da qualidade de vida e estabelecendo uma relação de diálogo e, consequentemente, de estímulo a reflexão. ${ }^{(24)}$

Dentre as etapas para elaboração de uma tecnologia educativa está uma busca vasta na literatura. ${ }^{(19,25)}$ A realização da scoping review permite a composição de base teórica e possibilita aos autores organizar, estruturar e selecionar conteúdos, contribuindo, dessa forma, para a formação do material educativo, como ocorreu neste estudo sobre o autocuidado domiciliar após cirurgias ginecológicas. (26) Tal conteúdo se faz importante, uma vez que entende-se que a recuperação pós-operatória é um processo complexo, que requer uma visão holística do restabelecimento dos aspectos, fisiológicos, psicológicos, sociais e econômicos. ${ }^{(27)}$

Após a elaboração do material educativo, é importante buscar sua validação. Para tanto, ressalta-se a diversidade de áreas profissionais que compuseram o grupo de juízes avaliadores. Tal variedade destaca-se como um aspecto favorável, pois possibilita a junção de diversos saberes e conhecimentos específicos, uniformizando as condutas e as orientaçóes de maneira multidisciplinar. ${ }^{(28,29)}$

A partir da avaliação da cartilha pelos juízes, evidenciou-se que esta apresentou valores considerados aceitáveis para sua utilização, tendo em vista que o escore médio do SAM e o Coeficiente de Validade de Conteúdo foram aceitáveis, o que demonstra sua validade. Outros estudos metodológicos de construção e validação de cartilhas também apresentaram valores satisfatórios. ${ }^{(30,31)}$

Embora a adequação cultural foi considerada adequada por $83 \%$ dos juízes, a inadequação para os demais sugeria a necessidade de ajustes. Além disso, uma média de $6,7 \%$ e de $3,3 \%$ considerou as ilustraçôes inadequadas e não aplicáveis, respectivamente, sendo apropriadas modificaçóes para aproximar as mulheres em pós-operatório de cirurgias ginecológicas das informaçóes sobre os cuidados domiciliares e, consequentemente, auxiliar no processo de educação em saúde. Nesse contexto, as modificaçóes sugeridas pelos juízes foram realizadas e reforçaram a validação, o que contribuiu para que o objetivo estabelecido fosse atingido. Tal efetivação permitiu maior qualidade e confiabilidade nas informaçóes, assim como um melhor nível de coerência. ${ }^{(32)}$

Importante ressaltar que a cartilha também foi validada pelo público-alvo, uma vez que, dependendo do nível educacional, as pessoas podem requerer uma apresentação imagética e literária mais específica. $\mathrm{O}$ público-alvo apresentou variabilidade no nível de escolaridade, o que permitiu avaliar, de forma ampla, o nível de esclarecimento do material, visto que houve compreensão superior da cartilha por todas, inclusive aquelas que requereram auxílio do acompanhante para efetuar a leitura. Tais participantes sem escolaridade não foram excluídas, pois caracterizam grande parte do público que acessa o serviço de saúde público, para o qual a cartilha foi desenvolvida.

As pacientes avaliaram o material como "superior" e expuseram o papel informacional, de portabilidade e divulgação para familiares e acessibilidade às orientaçóes sobre o pós-operatório. Os materiais impressos possuem boa aceitabilidade do público-alvo, por permitirem que a leitura seja realizada em qualquer ambiente, contribuindo, de forma significativa, para a autonomia do paciente e sua melhor adequação ao tratamento, o que reduz complicaçóes. ${ }^{(33)}$

É importante enfatizar que diversos fatores podem interferir na obtenção da informação adequada sobre o pós-operatório de cirurgias ginecológicas (nível educacional, aspectos socioculturais, estresse do momento da alta, rotina do serviço e qualidade das orientaçóes fornecidas), o que pode acarretar no esquecimento ou na incompreensáo das informaçóes ou, até mesmo, na sua não obtenção. Portanto, possuir esse material educativo pode, além de proporcionar informaçóes pertinentes sobre os cuidados domiciliares, permitir a continuidade do tratamento em domicílio e reduzir a angústia de paciente e/ou cuidadores, devido ao seu caráter 
informativo, ao fácil entendimento e à completude de informações.

A cartilha representa uma contribuição significativa para área da saúde, com destaque para os profissionais que prestam assistência às pacientes em pós-operatório de cirurgias ginecológicas, na atenção básica ou hospitalar. Esse subsídio deve-se ao fato de o material educativo servir como estratégia para açóes de educação em saúde, visando ao esclarecimento das informaçôes e à construção de diálogo com as pacientes e seus familiares. ${ }^{(12,19,26,28)}$ Sendo assim, o material educativo apresentado pode ser uma alternativa para auxiliar na sensibilização das pacientes e dos familiares, estimulando a assunçáo de uma postura ativa em relação ao autocuidado e podendo propiciar maior adesáo ao tratamento.

Expóe-se o número mínimo de representantes do público-alvo, que se justifica pelo limite de tempo definido para a finalização do estudo. Todavia, não houve interferência na qualidade dos resultados, tendo em vista a diversidade sociodemográfica da população participante e a riqueza das informaçóes obtidas durante a coleta de dados junto a esse público, assim como a não inclusão de juízes de outras áreas do conhecimento, ao exemplo do design gráfico.

\section{Conclusão}

A produção do material educativo voltado para as necessidades de autocuidado domiciliar após cirurgias ginecológicas teve êxito em seu processo de desenvolvimento, assim como a validação por meio da contribuição de juízes especialistas (Suitability Assessment of Materials de $83 \%$ e Instrumento de Validação de Conteúdo Educativo em Saúde de 0,86) e público-alvo (Suitability Assessment of Materials de 100\%). As sugestôes dos juízes foram incorporadas à versão final. O público-alvo apresentou consideraçôes favoráveis ao material, categorizando-o como importante para o acesso, o esclarecimento, a divulgação e a prática do autocuidado no domicílio. A cartilha educativa mostrou-se um instrumento válido e confiável para ser utilizada na promoção da saúde de mulheres quanto aos cuidados durante pós-operatório de cirurgias ginecológicas no ambiente domiciliar.

\section{Colaborações}

Concepção e projeto ou análise e interpretação dos dados: Lins MLR, Macedo JQ; Redação do artigo ou revisão crítica relevante do conteúdo intelectual: Evangelista CB, Gomes GL, Macedo JQ; Aprovação final da versão a ser publicada: Lins MLR, Evangelista CB, Gomes GL, Macedo JQ.

\section{Referências}

1. Brasil. Ministério da Saúde. Departamento de informática do Sistema Único de Saúde (DATASUS). Sistema de Informações Hospitalares do SUS. Procedimentos Hospitalares do SUS - Por Local De Internação - Brasil. Brasília (DF): DATASUS; 2018 [citado 2018 Nov 29]. Disponível em: http://tabnet.datasus.gov.br/cgi/ deftohtm.exe?sih/cnv/qiuf.def

2. Coelho SM, Perez EL, Lins CD, Gomes MT, Bella ZI, Andres MP, et al. Epidemiological profile and postoperative complications of women undergoing gynecological surgery in a reference center in the northern brazilian legal amazon. Rev Col Bras Cir. 2015;42(6):372-6.

3. Lykke R, Blaakaer J, Ottesen B, Gimbel H. Pelvic organ prolapse (POP) surgery among Danish women hysterectomized for benign conditions: age at hysterectomy, age at subsequent POP operation, and risk of POP after hysterectomy. Int Urogynecol J. 2015;26(4):527-32.

4. Humalajärvi N, Aukee P, Kairaluoma MV, Stach-Lempinen B, Sintonen $H$, Valpas A, et al. Quality of life and pelvic floor dysfunction symptoms after hysterectomy with or without pelvic organ prolapse. Eur J Obste. Gynecol Reprod Biol. 2014;182:16-21.

5. Herraiz JL, Llueca JA, Colecha M, Catala C, Oliva C, Calpe AS, et al. Histerectomía total laparoscópica: estudio descriptivo de la experiencia en el Hospital Universitario General de Castellón. Prog Obstet Ginecol. 2015;58(10):441-5.

6. Gutierrez AL, Binda ML, Ramos JG. Early experience of robotic hysterectomy for treatment of benign uterine disease. Rev Bras Ginecol Obstet. 2016;38(9):450-5.

7. Chen ZW, Joli P, Feng ZQ, Rahim M, Pirró N, Bellemare ME. Female patient-specific finite element modeling of pelvic organ prolapse (POP). J Biomech. 2015;48(2):238-45.

8. Deffieux X, Thubertb T, Dononc L, Hermieud JF, Normande LL, Trichotf C. Chirurgie d'occlusion vaginale (colpocléisis) pour prolapsus génital : recommandations pour la pratique clinique. Progrès Urologie. 2016;26(S1):61-72.

9. Hinkle JL, Cheever KH. Brunner e Suddarth: tratado de enfermagem médico-cirúrgica. 13ª ed. Rio de Janeiro: Guanabara Koogan; 2016.

10. Pereira SK, Santana RF, Morais VS, Soares TS, Silva DM. Discharge planning in post-operative of elderly: multiple cases study. J Res Fundam Care Online. 2016;8(4):4949-55.

11. Santos FD, Nunes SF, Pascoal LM, Silva JO, Almeida RP. Educação em saúde para pacientes no pós-operatório de cirurgias torácicas e abdominais. Rev Ciênc Ext. 2015;11(1):171- 7.

12. Sabino ML, Brasil DR, Caetano JA, Santos MC, Alves MD. Uso de tecnologia leve-dura nas práticas de enfermagem: Análise de conceito. Aquichan. 2016;16(2):230-9. 
13. Vasconcelos TB, Lourenço DR, Cardoso AR, Macena RH, Bastos VP, Matoso GR. Cartilha educativa para orientação dos profissionais de saúde sobre os equipamentos de proteção individual. Rev Gestão \& Saúde. 2015;6(1):232- 44.

14. Polit DF, Beck CT. Fundamentos de pesquisa em enfermagem: avaliação de evidências para a prática da enfermagem. 9a ed. Porto Alegre: Artmed; 2018.

15. Nascimento $\mathrm{MH}$, Teixeira E. Educational technology to mediate care of the "kangaroo family" in the neonatal unit. Rev Bras Enferm. 2018;71(Suppl 3):1370-7.

16. Pasquali, L. Psicometria: teoria dos testes na psicologia e na educação. Petrópolis: Vozes; 2017.

17. Echer IC. Elaboração de manuais de orientação para o cuidado em saúde. Rev Lat Am Enfermagem. 2005;13(5):729-36.

18. Horta WA. Processo de enfermagem. Rio de Janeiro: Guanabara Koogan; 2011.

19. Oliveira MC, Lucena AF, Echer IC. Neurological sequelae: preparation of a guidance manual for Health care. J Nurs UFPE Online. 2014;8(6):1597-603.

20. Sousa CS, Turrina RN, Poveda VB. Translation and adaptation of the instrument "suitability Assessment of materials" (sam) into portuguese. Rev Enferm UFPE Online. 2015;9(5):7854-61.

21. Leite SS, Áfio AC, Carvalho LV, Silva JM, Almeida PC, Pagliuca LM. Construction and validation of an Educational Content Validation Instrument in Health. Rev Bras Enferm. 2018;71(Suppl 4):1732-8.

22. Bardin L. Análise de conteúdo. São Paulo: Edições 70; 2016.

23. Brasil. Ministério da Saúde. Conselho Nacional de Saúde. Resolução № 466, de 12 de dezembro de 2012 [Internet]. Brasília (DF): Ministério da Saúde; 2012 [citado 2021 Fev 13]. Disponível em: https://bvsms. saude.gov.br/bvs/saudelegis/cns/2013/res0466_12_12_2012.html
24. Mallmann DG, Galindo Neto NM, Sousa JC, Vasconcelos EM. Health education as the main alternative to promote the health of the elderly. Ciênc Saúde Coletiva. 2015;20(6):1763-72. Review.

25. Varela Al, Rosa LM, Rodunz V, Salum NC, Souza Al. Educational booklet for patients in palliative care and their families: Construction strategies. Rev Enferm UFPE Online. 2017;11(Suppl 7):2955-62.

26. Oliveira SC, Lopes MV, Fernandes AF. Development and validation of an educational booklet for healthy eating during pregnancy. Rev Lat Am Enfermagem. 2014;22(4):611-20.

27. Ferraz SM, Moreira JP, Mendes LC, Amaral TM, Andrade AR, Santos AR, et al. Evaluation of the quality of recovery and the postoperative health status after elective surgery. Rev Bras Anestesiol. 2018;68(6):577-83.

28. Lima AC, Bezerra KC, Sousa DM, Rocha JF, Oriá MO. Development and validation of a booklet for prevention of vertical HIV transmission. Acta Paul Enferm. 2017;30(2):181-9.

29. Moura $H$, Silva AF, Rocha AE, Lima LH, Moreira TM, Silva AR. Construção e validação de material educativo para prevenção de síndrome metabólica em adolescentes. Rev Lat Am Enfermagem. 2017;25:e 2934

30. Sabino LM, Ferreira AM, Joventino ES, Lima FE, Penha JC, Lima KF, et al. Elaboration and validation of a reader on childhood diarrhea prevention. Acta Paul Enferm. 2018;31(3):233-9.

31. Silveira MB, Saldanha RS, Leite JC, Silva TO, Silva T, Filippin LI. Construction and validation of content of one instrument to assess falls in the elderly. einstein (São Paulo). 2018;16(2):1-8.

32. Vasconcelos SS, Gomes IL, Barbalho EV, Gouveia SS, Gouveia GP. Validação de uma cartilha sobre a detecção precoce do transtorno do espectro autista. Rev Bras Promoç Saúde. 2018;31(4):1-7.

33. Benevides JL, Coutinho JF, Pascoal LC, Joventino ES, Martins MC, Gubert FA, et al. Development and validation of educational technology for venous ulcer care. Rev Esc Enferm USP. 2016;50(2):309-16. 